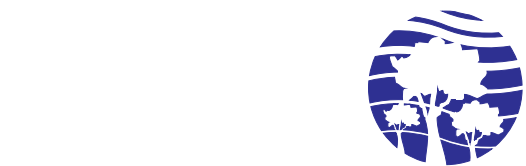

E N F L O

Ecologia e Nutrição Florestal

www.ufsm.br/enflo

\title{
Cinzas de madeira na produção de mudas de eucalipto ${ }^{1}$
}

\author{
Cristiane Ramos Vieira ${ }^{2}$; Oscarlina Lúcia dos Santos Weber ${ }^{3}$
}

\begin{abstract}
Resumo: A cinza de madeira, embora pouco utilizada na composição de substrato para produção de mudas, pode conter nutrientes prontamente disponíveis e, por conseguinte, aumentar as condições de fertilidade do substrato. Por isso, foi realizado experimento com o objetivo de verificar a combinação de: solo, substrato comercial (Plantmax®) e cinzas de madeira, mais adequada para a produção de mudas de Eucalyptus camaldulensis. As mudas foram produzidas em tubetes com capacidade para $160 \mathrm{~cm}^{3}$, com uso de sementes germinadas em areia e vermiculita. Ao atingirem $15 \mathrm{~cm}$ de altura, as plantas foram transplantadas para os tratamentos: $100 \%$ solo; $75 \%$ solo $+25 \%$ cinzas; $75 \%$ Plantmax ${ }^{\circledR}+25 \%$ cinzas; $50 \%$ solo + $50 \%$ cinzas; $50 \%$ Plantmax ${ }^{\circledR}+50 \%$ cinzas; $50 \%$ solo $+25 \%$ Plantmax ${ }^{\circledR}+25 \%$ cinzas, dispostos em delineamento inteiramente casualizado, com 10 repetições. A avaliação do crescimento ocorreu 90 dias após o transplante, com a medição da altura da parte aérea, diâmetro de colo, biomassa de folhas, biomassa de caule, biomassa de raízes e concentrações de nutrientes nas folhas. As combinações de substratos que proporcionaram o maior crescimento das mudas de E. camaldulensis foram $50 \%$ solo $+50 \%$ cinzas e $50 \%$ Plantmax ${ }^{\circledR}+50 \%$ cinzas.
\end{abstract}

Palavras-chave: Eucalyptus camaldulensis; Matéria Orgânica; Substrato; Produção de Mudas.

\section{Wood ash on eucalyptus seedling production}

\begin{abstract}
The wood ash, although little used in the composition of substrates for seedlings production, can contain readily available nutrients and, therefore, increase the fertility conditions of the substrate. Because of it was carried out experiment in nursery in order to verify the combination of: soil, commercial substrate (Plantmax ${ }^{\circledR}$ ) and plant ashes, more suitable for the production of Eucalyptus camaldulensis seedlings. The seedlings were grown in plastic tubetes with a capacity of $160 \mathrm{~cm}^{3}$ using seeds germinated in sand and vermiculite. When they reaching $15 \mathrm{~cm}$ of height, the plants were transplanted to the treatments: $100 \%$ soil; $75 \%$ soil $+25 \%$ ash; $75 \%$ Plantmax ${ }^{\circledR}+25 \%$ ash; $50 \%$ soil $+50 \%$ ash; $50 \%$ Plantmax ${ }^{\circledR}+50 \%$ ash; $50 \%$ soil $+25 \%$ Plantmax ${ }^{\circledR}+25 \%$ ashes, arranged in a randomized design with 10 repetitions. The evaluation of the growth occurred 90 days after transplantation, with the measurement of shoot height, diameter collect, the leaf biomass, stem biomass, roots biomass and concentrations of nutrients in the leaves of seedlings. The combinations of substrates that provided the greatest growth of E. camaldulensis seedlings were 50\% solo $+50 \%$ ash and 50\% Plantmax ${ }^{\circledR}+50 \%$ ash.
\end{abstract}

Keywords: Eucalyptus camaldulensis; Organic Matter; Substrate; Seedlings Production.

\footnotetext{
${ }^{1}$ Recebido em 21.07.2017 e aceito para publicação como artigo científico em 17.10.2017.

2 Engenheira Florestal, Dra ${ }^{\mathrm{a}}$. Professora do curso de Agronomia da Universidade de Cuiabá - UNIC. E-mail: <cris00986@ hotmail.com>. ${ }^{3}$ Engenheira Agrônoma, Dra ${ }^{\mathrm{a}}$. Professora Associada do Departamento de Solos e Engenharia Rural - FAAZ/UFMT. E-mail: <oscsan@uol.com.br>.
} 


\section{Introdução}

Os solos sob Cerrado são, em geral, de elevada acidez, altos teores de $\mathrm{Al}$ trocável, baixa disponibilidade de $\mathrm{Ca}, \mathrm{Mg}$ e, de $\mathrm{P}$ na forma disponível, o que compromete o crescimento das plantas e a produtividade das culturas. De acordo com Silva et al. (2008) e Favare et al. (2012), o uso de corretivos e fertilizantes é fundamental na formação de mudas, especialmente quando se utiliza, para a preparação de substrato, solos ácidos e pobres em nutrientes como os de Cerrado.

A cinza vegetal é um resíduo proveniente da queima da madeira que, dependendo de sua origem, pode ser utilizado como adubo (Nkana et al., 1998; Osaki e Darolt, 1991; Severino et al. 2006). Cutter e Murphy (1978), explicam que, os principais componentes minerais da madeira são $\mathrm{Ca}, \mathrm{K}$ e $\mathrm{Mg}$; sendo $\mathrm{Ca}$ o elemento em maior quantidade, chegando a representar 50\%, seguido respectivamente, pelo $\mathrm{K}, \mathrm{Mg}, \mathrm{Mn}, \mathrm{Na}$, $\mathrm{P}$, entre outros. Dessa forma, as cinzas compõem-se de quantidades razoáveis de macro e micronutrientes e podem possuir características corretivas de acidez em solo e, potencial para ser usado como fertilizante orgânico (Oliveira et al., 2006). Além disso, possui caráter alcalinizante, que pode ser atribuído à abundância de óxidos, hidróxidos e carbonatos, principalmente de $\mathrm{Ca}, \mathrm{Mg}$ e $\mathrm{K}$ (Etiegni e Campbell, 1991).

Considerando essas características, as cinzas podem ser utilizadas na produção de mudas como parte componente do substrato, o que garante melhorias nas condições nutricionais do mesmo e a redução dos gastos com adubações. Porém, para isso, há que se conhecer a espécie e seus requerimentos nutricionais (Feitosa et al., 2011).

A espécie estudada foi o Eucalyptus camaldulensis Dehn., que é nativa da Austrália e bastante utilizada em plantios comerciais no Brasil devido a sua rusticidade e adaptabilidade às condições de baixa fertilidade, podendo ser utilizada também em áreas de Cerrado. Segundo Ibá (2015), a área plantada com Eucalyptus no Brasil atingiu 5,6 milhões de hectares no ano de
2015, total de 5.630.607 hectares, o que representa $72 \%$ do total de árvores plantadas. A maior parte desse plantio concentra-se nos estados de Minas Gerais com $25 \%$ e, São Paulo com $17 \%$.

Portanto, é necessário o desenvolvimento de técnicas para produção de mudas da espécie que possibilitem obter mudas de qualidade, com baixo custo em investimento. Nesse sentido, houve nos últimos anos um aumento nas pesquisas com substratos orgânicos para a produção de mudas de espécies florestais. De acordo com Lima et al. (2006), a utilização dos resíduos orgânicos se tornou uma tendência na composição de substratos para produção de mudas, contribuindo para o fornecimento de nutrientes e características físicas do meio de cultivo.

No entanto, são poucos os trabalhos que utilizam as cinzas de madeira na composição de substrato para a produção de mudas. A maior parte das pesquisas realizadas utilizam espécies de cunho agronômico. Silva et al. (2013), verificaram que a adição de cinzas de madeira no substrato comercial, juntamente com o gesso, não favoreceu o desenvolvimento das mudas de Passiflora edulis Sims f. flavicarpa Deg., exceto nas menores proporções utilizadas (0 e 1,6\%). Ferreira et al. (2009), verificaram que o sistema radicular das mudas de Annona crassiflora Mart. desenvolveu-se melhor em substratos em que não foi feita a aplicação de calcário ou de cinzas.

Diante disso, o objetivo desse estudo foi avaliar a utilização de cinzas de madeira em combinação com solo e substrato comercial, no crescimento inicial de mudas de $E$. camaldulensis.

\section{Material e métodos}

$\mathrm{O}$ experimento foi instalado em casa de vegetação construída com material telado tipo sombrite branco e coberta com telha de amianto, sem controle de temperatura, localizada na Faculdade de Agronomia, Medicina Veterinária e Zootecnica (FAMEVZ) da Universidade Federal de Mato Grosso (UFMT), em Cuiabá, no 
período de julho a outubro de 2015.

As sementes de E. camaldulensis foram coletadas de 20 árvores matrizes, espaçadas em $100 \mathrm{~m}$, em um plantio localizado no município de Dom Aquino-MT. Essas sementes foram colocadas para germinar em tubetes com capacidade para $160 \mathrm{~cm}^{3}$, preenchidos com areia lavada e vermiculita, cada tubete com quatro a cinco sementes. Aos 30 dias após a semeadura, quando as plântulas atingiram $5 \mathrm{~cm}$ de altura, realizou-se o raleamento para deixar apenas uma por tubete. Ao atingirem $15 \mathrm{~cm}$, as plantas foram transplantadas para tubetes com capacidade para $280 \mathrm{~cm}^{3}$, preenchidos com as combinações de substratos utilizadas no experimento.

Para a composição dos substratos utilizou-se o solo classificado como Latossolo VermelhoAmarelo Distrófico de textura franco arenosa (Embrapa, 2013), coletado da camada de $20 \mathrm{~cm}$, de área sob vegetação de Cerrado, localizada no Instituto Federal de Mato Grosso - São Vicente. $\mathrm{O}$ solo foi seco ao ar livre e peneirado em malha de $2 \mathrm{~mm}$.

O substrato comercial utilizado foi $o$ Plantmax ${ }^{\circledR}$, indicado para produção de mudas de espécies florestais. Segundo o fabricante, em sua composição constam: casca de pinus, vermiculita de granulometria fina e superfina e húmus.

As cinzas foram obtidas após a queima do caule de plantas de Tectona grandis L. f. e de Schizolobium amazonicum Huber ex Ducke, submetidas, anteriormente, ao plantio no campo pelo período de um ano. Essa queima foi realizada após a moagem do caule e ocorreu em mufla, a $500{ }^{\circ} \mathrm{C}$ durante 6 horas.

Os substratos foram combinados nas seguintes proporções: T1 - $100 \%$ solo (testemunha); $\mathrm{T} 2-75 \%$ solo $+25 \%$ cinzas; $\mathrm{T} 3-$ $75 \%$ Plantmax ${ }^{\circledR}+25 \%$ cinzas; $\mathrm{T} 4-50 \%$ solo + $50 \%$ cinzas; $\mathrm{T} 5-50 \%$ Plantmax ${ }^{\circledR}+50 \%$ cinzas; T6 $-50 \%$ solo $+25 \%$ Plantmax ${ }^{\circledR}+25 \%$ cinzas. Essas combinações deram origem aos seis tratamentos testados no experimento, com 10 repetições, dispostos em delineamento inteiramente casualizado. Essas combinações de substratos foram utilizadas para preencher os tubetes de polipropileno de formato cônico com estrias, perfurados na extremidade inferior, com capacidade para $280 \mathrm{~cm}^{3}$. Porém, antes das mudas serem transplantadas, uma amostra de cada tratamento foi retirada para realização da análise química, sem análise unicamente das cinzas, segundo métodos da Embrapa (1997) (Tabela 1).

Tabela 1 - Características químicas dos substratos

Table 1- Chemical characteristics of substrates

\begin{tabular}{|c|c|c|c|c|c|c|c|c|c|c|c|c|c|}
\hline \multirow{2}{*}{ Trat } & pH & $\mathbf{H}+\mathbf{A l}$ & Al & $\mathrm{Ca}^{2+}$ & $\mathbf{M g}^{2+}$ & $\mathbf{K}$ & $\mathbf{P}$ & SB & $\mathbf{T}(\mathbf{p H 7 , 0 )}$ & $\mathbf{t}$ & $\mathbf{V}$ & $\mathbf{m}$ & $\mathbf{N}$ \\
\hline & $\mathrm{CaCl}_{2}$ & \multicolumn{3}{|c|}{------ $\mathrm{cmol}_{\mathrm{c}} \mathrm{dm}^{-3}$} & ---- & \multicolumn{2}{|c|}{-- $\mathrm{mg} \mathrm{dm}^{-3}--$} & \multicolumn{3}{|c|}{----- $\mathrm{cmol}_{\mathrm{c}} \mathrm{dm}^{-3}$} & \multicolumn{2}{|c|}{--- \% --- } & $\mathrm{g} \mathrm{kg}^{-1}$ \\
\hline $\mathrm{T} 1$ & 4,4 & 10,0 & 0,3 & 1,8 & 1,8 & 4,2 & 40,9 & 3,6 & 13,6 & 3,9 & 26,0 & 7,7 & 4,8 \\
\hline $\mathrm{T} 2$ & 4,8 & 7,0 & 0,3 & 5,6 & 3,1 & 144,1 & 91,3 & 9,1 & 16,1 & 9,4 & 56,0 & 3,2 & 6,4 \\
\hline T3 & 6,2 & 5,2 & 0,0 & 3,6 & 3,8 & 247,7 & 20,6 & 8,0 & 13,2 & 8,0 & 61,0 & 0,0 & 4,2 \\
\hline $\mathrm{T} 4$ & 5,8 & 5,0 & 0,1 & 5,8 & 4,7 & 180,2 & 96,1 & 11,0 & 16,0 & 11,1 & 69,0 & 0,9 & 4,2 \\
\hline T5 & 5,4 & 8,0 & 0,2 & 4,1 & 3,1 & 85,6 & 28,7 & 7,4 & 15,4 & 7,6 & 48,0 & 2,6 & 4,2 \\
\hline T6 & 5,2 & 7,5 & 0,2 & 4,0 & 4,1 & 103,6 & 32,8 & 8,4 & 15,9 & 8,6 & 53,0 & 2,3 & 4,8 \\
\hline
\end{tabular}

*pH em $\mathrm{CaCl}_{2}$ - relação 1:2,5; $\mathrm{H}+\mathrm{Al}$ - em acetato de cálcio; $\mathrm{Al}^{3+}, \mathrm{Ca}^{2+}$ e $\mathrm{Mg}^{2+}$ - em $\mathrm{KCl} ; \mathrm{P}$ e $\mathrm{K}$ - em Mehlich; $\mathrm{SB}$ - soma de bases; $\mathrm{T}$ $(\mathrm{pH} 7,0)$ - capacidade de troca de cátions a $\mathrm{pH} 7,0 ; \mathrm{t}$ - capacidade efetiva de troca de cátions; $\mathrm{V}$ - saturação por bases, em \%; $\mathrm{m}$ - saturação por $\mathrm{Al}$, em \%; $\mathrm{N}$ - digestão sulfúrica. 
Após o transplante as plantas passaram pelo processo de adaptação, considerando adaptadas quando apresentaram novas brotações, o que ocorreu após 15 dias. Em seguida, realizou-se o acompanhamento do crescimento das plantas de E. camaldulensis por 90 dias.

Ao término do experimento realizaram-se as biometrias das características morfológicas: altura $(\mathrm{H})$, em $\mathrm{cm}$, medida da superfície do solo até a última folha e; diâmetro de colo (DC), em $\mathrm{mm}$, medido com paquímetro digital. Para obtenção da biomassa, as mudas foram retiradas do substrato, seccionadas em folhas, caule e raízes e, em seguida as raízes foram lavadas em água corrente. $\mathrm{O}$ material vegetal foi levado à estufa de circulação forçada de ar a $65^{\circ} \mathrm{C}$ até peso constante. Após secagem, foi pesado em balança analítica com precisão de $0,01 \mathrm{~g}$.

O material foliar seco foi moído em moinho tipo Wiley para determinação das concentrações de macronutrientes e de B, após as digestões sulfúrica e nitro-perclórica, seguindo métodos de Malavolta et al. (1997). A saber: $N$ total por semi-micro Kjeldahl; $\mathrm{P}$ por colorimetria do metavanadato; $\mathrm{S}$ por turbidimetria do sulfato de bário; K por fotometria de chama de emissão; $\mathrm{Ca}$ e $\mathrm{Mg}$ por quelatometria com EDTA e B por colorimetria da azometina $\mathrm{H}$.

Os dados foram interpretados por meio da análise de variância e a comparação de médias foi realizada pelo método de Tukey ao nível de $5 \%$ de probabilidade de erro utilizando o programa estatístico Assistat 7.6 beta, da UFCG, após constatação da normalidade dos mesmos.

\section{Resultados e Discussão}

Crescimento das mudas de Eucalyptus camaldulensis

O crescimento em altura, a biomassa seca do caule e a biomassa seca das raízes foram influenciados pelas combinações de cinzas, substrato comercial e solo, utilizados para a composição do substrato para produção de mudas de E. camaldulensis (Tabela 2).

Tabela 2 - Crescimento em altura $(\mathrm{cm})$, em diâmetro $(\mathrm{mm})$, comprimento da raiz $(\mathrm{cm})$, biomassa de folhas, caule e raiz $(\mathrm{g})$ das mudas de Eucalyptus camaldulensis em diferentes combinações de substratos

Table 2 - Growth in height $(\mathrm{cm})$, diameter $(\mathrm{mm})$, root length $(\mathrm{cm})$, leaf, stem and root biomass $(\mathrm{g})$ of Eucalyptus camaldulensis seedlings in different combinations of substrates

\begin{tabular}{ccccccc}
\hline Tratamento & H & DC & Raiz & BioFolha & BioCaule & BioRaiz \\
\hline T1 & $35,50 \mathrm{a}$ & $2,67 \mathrm{a}$ & $27,50 \mathrm{a}$ & $0,68 \mathrm{~b}$ & $0,49 \mathrm{a}$ & $0,53 \mathrm{a}$ \\
T2 & $33,17 \mathrm{ab}$ & $2,47 \mathrm{a}$ & $21,67 \mathrm{a}$ & $1,02 \mathrm{ab}$ & $0,42 \mathrm{ab}$ & $0,54 \mathrm{a}$ \\
T3 & $36,83 \mathrm{a}$ & $2,53 \mathrm{a}$ & $23,83 \mathrm{a}$ & $1,07 \mathrm{ab}$ & $0,45 \mathrm{a}$ & $0,62 \mathrm{a}$ \\
T4 & $33,83 \mathrm{ab}$ & $2,62 \mathrm{a}$ & $25,83 \mathrm{a}$ & $1,19 \mathrm{a}$ & $0,50 \mathrm{a}$ & $0,58 \mathrm{a}$ \\
T5 & $31,00 \mathrm{ab}$ & $2,50 \mathrm{a}$ & $24,83 \mathrm{a}$ & $1,21 \mathrm{a}$ & $0,48 \mathrm{a}$ & $0,50 \mathrm{a}$ \\
T6 & $27,00 \mathrm{~b}$ & $2,32 \mathrm{a}$ & $25,83 \mathrm{a}$ & $1,11 \mathrm{ab}$ & $0,32 \mathrm{~b}$ & $0,46 \mathrm{a}$ \\
\hline F & 3,43 & $2,00 \mathrm{~ns}$ & $1,23 \mathrm{~ns}$ & $3,42^{*}$ & $6,30^{* *}$ & $1,21 \mathrm{~ns}$ \\
DMS & 8,15 & 0,37 & 7,83 & 0,45 & 0,12 & 0,21 \\
CV(\%) & 14,11 & 8,45 & 17,96 & 24,40 & 14,97 & 22,27
\end{tabular}

* Médias seguidas pela mesma letra, na coluna, não diferem entre si pelo teste Tukey 5\%. T1 - 100\% solo (testemunha); T2 - 75\% solo + $25 \%$ cinzas; $\mathrm{T} 3-75 \%$ Plantmax ${ }^{\circledR}+25 \%$ cinzas; $\mathrm{T} 4-50 \%$ solo $+50 \%$ cinzas; $\mathrm{T} 5-50 \%$ Plantmax ${ }^{\circledR}+50 \%$ cinzas; $\mathrm{T} 6-50 \%$ solo $+25 \%$ Plantmax ${ }^{\circledR}+25 \%$ cinzas. 
O crescimento em altura das mudas de $E$. camaldulensis foi influenciado pela adição de cinzas, principalmente, no substrato na proporção de T3 (75\% Plantmax® ${ }^{\circledR}+25 \%$ cinzas), com média de $36,83 \mathrm{~cm}$, que foi estatisticamente semelhante ao T1 (100\% solo), com média $35,50 \mathrm{~cm}$, sendo estes, $26,7 \%$ e $24 \%$ maiores que as de T6 (50\% solo $+25 \%$ Plantmax ${ }^{\circledR}+25 \%$ cinzas), respectivamente. Portanto, a adição de baixo percentual de cinzas foi suficiente para proporcionar o crescimento das mudas, pois estas são, em geral, ricas em nutrientes prontamente disponíveis, porém, isso dependerá da origem das mesmas. Percebeu-se também que, o substrato comercial precisou da adição de cinzas para promover a melhoria das condições para o crescimento das mudas. $\mathrm{O}$ que indica que apesar de ser indicado para espécies florestais, o substrato comercial não melhorou as condições físicas e/ou químicas para o crescimento das mudas de E. camaldulensis.

$\mathrm{O}$ resultado para o crescimento em altura no tratamento $100 \%$ solo pode estar relacionado com as condições nutricionais que foram favoráveis para essas características, aliada às exigências da espécie. Porém, para a obtenção de mudas de qualidade há que se atentar para as demais características, como diâmetro e biomassa. Elas estão relacionadas com as condições proporcionadas pelo substrato e podem garantir mudas com maior capacidade de sobrevivência no campo.

Não houve diferença estatística no crescimento em diâmetro, porém, em todos os tratamentos se observou médias superiores a 2 $\mathrm{mm}$, o que indica crescimento adequado das mudas. Segundo Xavier et al. (2009), a altura e o diâmetro do colo das mudas para serem plantadas no campo devem ser de 20 a $40 \mathrm{~cm} \mathrm{e}$ 2,0 $\mathrm{mm}$, respectivamente, nesse caso, verificouse crescimento favorável em todos os tratamentos. Porém, considerando que, busca-se em viveiros, a produção de mudas em qualidade e em quantidade, T6 $(50 \%$ solo $+25 \%$ Plantmax ${ }^{\circledR}+25 \%$ cinzas) poderia não ser indicado porque demandou mais tempo para atingir os valores propostos para altura $\mathrm{e}$ diâmetro.
Essas médias para o crescimento em altura e em diâmetro foram semelhantes as observadas por Freitas et al. (2010), ao trabalharem com Eucalyptus urophylla S. T. Blake produzido em $40 \%$ de casca de eucalipto decomposta $+30 \%$ de torta de filtro + fibra de coco, que obtiveram mudas com médias de $39 \mathrm{~cm}$ de altura e $2,60 \mathrm{~mm}$ de diâmetro. Silva et al. (2012), observaram, para mudas de E. urophylla x Eucalyptus grandis, altura de até $37 \mathrm{~cm}$ de altura, com uso de substrato casca de arroz carbonizado e fibra de coco.

Porém, as médias para altura e diâmetro do presente experimento foram superiores às observadas por Petter et al. (2012), ao utilizar substrato comercial acrescido com Biochar para a produção de mudas de E. urophylla e $E$. citriodora, considerando que, nesse trabalho, as medições foram realizadas aos 120 dias. Aos resultados obtidos por Silva et al. (2014), que utilizaram substratos orgânicos para a produção de mudas de E. grandis. Aos obtidos por Kratz e Wendling (2013), que produziram mudas de Eucalyptus dunnii Maiden., em substratos contendo vermiculita, fibra de coco e casca de arroz carbonizada. E aos obtidos por Lôbo et al. (2014), que produziram mudas de $E$. camaldulensis em substrato adubado com NPK. Nesse último caso, a maior altura observada foi de $16,41 \mathrm{~cm}$ e diâmetro de 1,31 mm. Demonstrando que, as combinações sugeridas com substrato comercial, cinzas e solo, no presente caso, podem ser favoráveis para a produção de mudas.

Porém, deve-se atentar para as combinações entre as cinzas e o substrato comercial, pois, dependendo das proporções utilizadas, podem ocorrer aumentos significativos nas características químicas do solo, como observado na Tabela 1. Essas proporções podem causar interações desfavoráveis e, consequentemente, prejudicar o crescimento das plantas.

Para o comprimento radicular, verificaram-se médias superiores a $20 \mathrm{~cm}$, sem diferença estatística entre os tratamentos. Esse crescimento radicular indica condições favoráveis durante a produção das mudas, o que 
é importante porque, segundo Freitas et al. (2005), deformações radiculares após o plantio e o plantio de mudas menores em função da restrição no viveiro, podem reduzir ou atrasar o crescimento das plantas no campo. Nesse caso, o crescimento do sistema radicular pode ter favorecido a absorção de água e de nutrientes e contribuído para o crescimento total das mudas de E. camaldulensis.

As produções de biomassa nas folhas, no caule e nas raízes também foram influenciadas pelas combinações de substratos testadas na produção de mudas de E. camaldulensis. Para a biomassa das folhas, as cinzas foram importantes nas proporções de $\mathrm{T} 4(50 \%$ solo + $50 \%$ cinzas) e de T5 (50\% Plantmax ${ }^{\circledR}+50 \%$ cinzas), atingindo médias de $1,19 \mathrm{~g}$ e $1,21 \mathrm{~g}$, respectivamente, que foram $42,8 \%$ e $43,8 \%$ superiores em comparação com T1 (100\% solo) com média de 0,68 g. Comprovando que o crescimento em altura em diâmetro devem ser acompanhados de adequada produção de biomassa, para garantir mudas mais vigorosas e aptas ao plantio.

De acordo com Gomes e Paiva (2006), a massa seca da parte aérea, indica a rusticidade de uma muda, sendo que os maiores valores representam muda mais lignificada e rústica, com maior potencial de produção em ambientes com condições adversas. Este resultado pode estar relacionada com o fato de as cinzas disponibilizarem nutrientes que estão ligados ao processo fotossintético, como N, P e K. Além disso, funcionam como condicionadoras do solo, aumentando os teores de bases e, por consequência, a saturação por bases e $\mathrm{o} \mathrm{pH}$, melhorando suas condições químicas, como observado ao analisar as características químicas das composições realizadas para o experimento.

$\mathrm{Na}$ biomassa do caule, T1 (100\% solo), T3 $(75 \%$ Plantmax $®+25 \%$ cinzas), T4 $(50 \%$ solo $+50 \%$ cinzas) e T5 (50\% Plantmax ${ }^{\circledR}+50 \%$ cinzas) foram os melhores, com médias $34,7 \%$, $28,9 \%, 36 \%$ e $33,3 \%$, respectivamente, superiores ao T6 (50\% solo + 25\% Plantmax ${ }^{\circledR}+$ $25 \%$ cinzas). A combinação de substrato comercial com cinzas pode ter limitado o crescimento e a produção de biomassa devido à interação negativa entre alguns nutrientes, presentes em ambos os substratos, o que também foi verificado no crescimento em altura. Ou ainda, às características físicas dos dois substratos, que propiciou uma camada mais adensada na superfície e que pode ter dificultado a infiltração de água e, dessa forma, ter ocasionado a redução da disponibilidade de nutrientes para as plantas.

Nesse caso, as combinações de solo com Plantmax ${ }^{\circledR}$ e cinzas, nas condições de T4 $(50 \%$ solo $+50 \%$ cinzas) e de T5 (50\% Plantmax ${ }^{\circledR}+$ $50 \%$ cinzas) foram as que proporcionaram as condições mais favoráveis para o crescimento inicial das mudas de E. camaldulensis.

Nutrição de mudas de Eucalyptus camaldulensis

Os resultados para os teores de macronutrientes e de $\mathrm{B}$, nas folhas das mudas de E. camaldulensis, após o crescimento em diferentes combinações de substratos estão na Tabela 3.

Não houve diferença para os teores de $\mathrm{N}$ entre os tratamentos testados, além disso, estes foram considerados menores que os propostos por Malavolta et al. (1997), de 12 a $35 \mathrm{~g} \mathrm{~kg}^{-1}$. Porém, isso não limitou o crescimento das mudas de $E$. camaldulensis, assim como não houve aparecimento de sintoma de deficiência. Portanto, as concentrações existentes em cada um dos componentes do substrato foram suficientes para a demanda que a espécie necessitou. E pode ter contribuído para a média em T1 (100\% solo) ter sido igual à de T3 $(75 \%$ Plantmax ${ }^{\circledR}+25 \%$ cinzas) ao analisar o crescimento em altura.

Os teores de $\mathrm{P}$ foram influenciados pela composição do substrato $\mathrm{e}$, a maior média foi observada em T2 (100\% Plantmax $\left.{ }^{\circledR}\right)$, provavelmente devido às concentrações de $\mathrm{P}$ presentes no substrato. Porém, todos os tratamentos apresentaram médias superiores às recomendadas por Malavolta et al. (1997), entre 1,0 e $2,3 \mathrm{~g} \mathrm{~kg}^{-1}$. O que não limitou o crescimento das mudas de E. camaldulensis, porque a espécie demonstrou uma alta demanda por $\mathrm{P}$ na fase inicial de desenvolvimento. Esses resultados 
também estão relacionados com o aumento do pH após as combinações entre substratos, o que reduziu o teor de $\mathrm{Al}$ e a acidez do solo, aumentando a disponibilidade de P. Semelhante ao observado por Prado et al. (2002), ao constatarem que a aplicação de cinzas promoveu a neutralização da acidez do solo, de forma que houve efeito positivo no valor do $\mathrm{pH}$ e redução na concentração de $\mathrm{H}+\mathrm{Al}$.

Tabela 3 - Teores de macronutrientes $\left(\mathrm{g} \mathrm{kg}^{-1}\right)$ e de B $\left(\mathrm{mg} \mathrm{kg}^{-1}\right)$, nas folhas das mudas de Eucalyptus camaldulensis em diferentes combinações de substratos

Table 3 - Macronutrients $\left(\mathrm{g} \mathrm{kg}^{-1}\right)$ and $\mathrm{B}\left(\mathrm{mg} \mathrm{kg}^{-1}\right)$ on the leaves of Eucalyptus camaldulensis seedlings in different combinations of substrates

\begin{tabular}{cccccccc}
\hline Trat. & $\mathbf{N}$ & $\mathbf{P}$ & $\mathbf{K}$ & $\mathbf{C a}$ & $\mathbf{M g}$ & $\mathbf{S}$ & $\mathbf{B}$ \\
\hline T1 & $9,69 \mathrm{a}$ & $7,11 \mathrm{c}$ & $7,24 \mathrm{c}$ & $1,22 \mathrm{a}$ & $0,65 \mathrm{~b}$ & $0,97 \mathrm{c}$ & $3,75 \mathrm{~d}$ \\
T2 & $9,29 \mathrm{a}$ & $11,14 \mathrm{a}$ & $11,77 \mathrm{bc}$ & $0,96 \mathrm{ab}$ & $0,96 \mathrm{ab}$ & $1,67 \mathrm{a}$ & $78,15 \mathrm{a}$ \\
T3 & $10,19 \mathrm{a}$ & $6,52 \mathrm{c}$ & $21,54 \mathrm{a}$ & $0,83 \mathrm{ab}$ & $1,11 \mathrm{a}$ & $0,87 \mathrm{c}$ & $37,22 \mathrm{c}$ \\
T4 & $9,57 \mathrm{a}$ & $9,12 \mathrm{~b}$ & $13,66 \mathrm{~b}$ & $0,96 \mathrm{ab}$ & $0,96 \mathrm{ab}$ & $1,64 \mathrm{ab}$ & $58,24 \mathrm{~b}$ \\
T5 & $9,41 \mathrm{a}$ & $9,09 \mathrm{~b}$ & $10,99 \mathrm{bc}$ & $0,77 \mathrm{~b}$ & $0,84 \mathrm{ab}$ & $1,06 \mathrm{bc}$ & $38,98 \mathrm{c}$ \\
T6 & $10,08 \mathrm{a}$ & $9,99 \mathrm{ab}$ & $13,27 \mathrm{~b}$ & $0,89 \mathrm{ab}$ & $0,77 \mathrm{ab}$ & $0,97 \mathrm{c}$ & $64,35 \mathrm{~b}$ \\
\hline F & $0,17 \mathrm{~ns}$ & $27,19 * *$ & $16,57 * *$ & $2,96 *$ & $4,07 * *$ & $6,82 * *$ & $86,94 * *$ \\
DMS & 3,79 & 1,46 & 5,08 & 0,39 & 0,35 & 0,60 & 12,27 \\
CV(\%) & 20,00 & 8,45 & 19,88 & 21,45 & 20,43 & 25,85 & 13,42
\end{tabular}

* Médias seguidas pela mesma letra, na coluna, não diferem entre si pelo teste Tukey 5\%. T1 - 100\% solo (testemunha); T2 - 75\% solo + $25 \%$ cinzas; $\mathrm{T} 3-75 \%$ Plantmax ${ }^{\circledR}+25 \%$ cinzas; $\mathrm{T} 4-50 \%$ solo $+50 \%$ cinzas; $\mathrm{T} 5-50 \%$ Plantmax ${ }^{\circledR}+50 \%$ cinzas; $\mathrm{T} 6-50 \%$ solo $+25 \%$ Plantmax ${ }^{\circledR}+25 \%$ cinzas.

Os teores de K também foram influenciados, principalmente pela combinação entre Plantmax ${ }^{\circledR}$ e cinzas, na proporção de T3 $(75 \%$ Plantmax ${ }^{\circledR}+25 \%$ cinzas), com teores acima do recomendado, enquanto em T1 (100\% solo) esses teores estiveram abaixo. Nesse caso, apenas em T1 e em T3 não se observou teores entre 10 e $15 \mathrm{~g} \mathrm{~kg}^{-1}$ de $\mathrm{K}$, recomendada por Malavolta et al. (1997). Portanto, a adição de Plantmax ${ }^{\circledR}$, de cinzas ou da combinação entre ambos, foram eficientes na disponibilização de $\mathrm{K}$, isso porque, altos teores foram observados desde a composição dos substratos, ao analisar os teores de $\mathrm{K}$ nos mesmos. Os teores dos substratos foram superiores ao combinar Plantmax ${ }^{\circledR}$ e/ou cinzas com solo, além disso, o solo, unicamente, possuía teor muito baixo de K, segundo Sousa e Lobato (2004). Isso favoreceu o crescimento do E. camaldulensis, pois, o $\mathrm{K}$ está relacionado com o processo fotossintético e com a regulação de água dentro das plantas (Malavolta et al., 1997).

A interação antagônica entre $\mathrm{K}$ e $\mathrm{Ca}$ pode ter influenciado nos teores de $\mathrm{Ca}$ nas mudas, pois, os maiores foram observados em T1 (100\% solo), no qual se verificou o menor teor de K. Porém, em todos os tratamentos as médias estiveram abaixo das recomendadas por Malavolta et al. (1997), para os quais essa faixa deve ser de 3,0 a 12,0 $\mathrm{g} \mathrm{kg}^{-1}$. Esses resultados podem ser explicados também pela baixa demanda de Ca nessa fase de crescimento, já que nenhum sintoma de deficiência foi observado. $\mathrm{O}$ mesmo foi constatado para os teores de $\mathrm{Mg}$, que deveriam estar entre 1,5 e 5,0 $\mathrm{g} \mathrm{kg}^{-1}$, segundo Malavolta et al. (1997), porém, o tratamento que mais se aproximou dessa faixa foi o T3 (75\% Plantmax ${ }^{\circledR}+25 \%$ cinzas), demonstrando que as cinzas vegetais utilizadas não são ricas em Ca e em $\mathrm{Mg}$, o que foi agravado pela interação 
antagônica com K.

Os maiores teores de $\mathrm{S}$ foram verificados em T2 (100\% Plantmax®), com média dentro da faixa recomendada por Malavolta et al. (1997), assim como em T4 (50\% solo $+50 \%$ cinzas), pois, permaneceram entre 1,4 e $2,0 \mathrm{~g} \mathrm{~kg}^{-1}$, demonstrando que, tanto o Plantmax ${ }^{\circledR}$ quanto as cinzas foram eficientes na liberação de $S$, o que melhorou as condições para crescimento das mudas.

Com relação ao B, apenas em T1 (100\% solo) se observou teores abaixo de $5 \mathrm{mg} \mathrm{kg}^{-1}$. Nos demais tratamentos, os teores foram superiores a $20 \mathrm{mg} \mathrm{kg}{ }^{-1}$, que é o nível recomendado por Malavolta et al. (1997). Contribuindo para a menor média na biomassa seca das folhas no T1. Nesse caso, T2 (100\% Plantmax $\left.{ }^{\circledR}\right)$ foi o que mais favoreceu a disponibilização de B para as mudas de E. camaldulensis. Isso ocorre porque os solos brasileiros, principalmente, os de Cerrado não são ricos em $\mathrm{B}$, já que a maior responsável pelo suprimento em B é a matéria orgânica, evidenciando que o substrato comercial e as cinzas foram capazes de liberar B em concentrações acima da adequada.

Portanto, o Plantmax ${ }^{\circledR}$ foi eficiente na liberação de $\mathrm{N}, \mathrm{P}, \mathrm{S}$ e $\mathrm{B}$, porém isso não garantiu o maior crescimento, porque, de acordo com Carvalho Filho et al. (2003), o crescimento não se deve apenas ao suprimento de nutrientes, mas também à melhoria de outros constituintes da fertilidade do solo como a aeração, o fornecimento de água, entre outros.

\section{Conclusões}

A combinação de cinzas vegetais, substrato comercial e solo pode ser utilizada para compor o substrato na produção de mudas de $E$. camaldulensis.

A adição de cinza vegetal ao substrato favoreceu a fertilidade do mesmo e, dessa forma, melhorou as condições para o crescimento das mudas de E. camaldulensis.

A melhor combinação dentre os substratos testados para a produção de mudas de $E$. camaldulensis foi composta por $50 \%$ solo $+50 \%$ cinzas e por $50 \%$ Plantmax $®+50 \%$ cinzas.

\section{Referências Bibliográficas}

CARVALHO FILHO, J. L. S. et al. Produção de mudas de jatobá (Hymenaea courbaril L.) em diferentes ambientes, recipientes e composições de substratos. Cerne, v. 9, n. 1, p. 109-118, 2003.

CUTTER, B. E.; MURPHY, W. K. Effects of potassium on growth and wood anatomy of Populus hybrid. Wood and Fiber Science, v. 9, n. 4, p. 282-288, 1978.

EMPRESA BRASILEIRA DE PESQUISA AGROPECUÁRIA - EMBRAPA. Serviço Nacional de Levantamento e Conservação de Solos. Manual de métodos de análise do solo. 2. ed. Rio de Janeiro: EMBRAPA, 1997. 212 p.

EMPRESA BRASILEIRA DE PESQUISA AGROPECUÁRIA - EMBRAPA. Sistema brasileiro de classificação de solos. 3.ed. Brasília: Embrapa. 2013. 353p.

ETIEGNI, L.; CAMPBELL, A. G. Physical and chemical characteristics of wood ash. Bioresource Technology, v. 37, p. 173-178, 1991.

FAVARE, L. G.; GUERRINI, I. A.; BACKES, C. Níveis crescentes de saturação por bases e desenvolvimento inicial de teca em um Latossolo de textura média. Ciência Florestal, v. 22, n. 4, p. 693-702, 2012.

FEITOSA, D. G. et al. Crescimento de mudas de gonçalo-alves (Astronium fraxinifolium) sob diferentes fontes e doses de nitrogênio. Revista Árvore, v. 35, n. 3, p. 401-411, 2011.

FERREIRA, R. B. et al. Desenvolvimento de mudas de Annona crassiflora Mart. (araticum) em substratos com cinza de bagaço de cana. Pesquisa Agropecuária Tropical, v. 39, n. 1, p. 18-24, 2009. 
FREITAS, T. A. S. et al. Desempenho radicular de mudas de eucalipto produzidas em diferentes recipientes e substratos. Revista Árvore, v. 29, p. 853-861, 2005.

FREITAS, T. A. S. et al. Produção de mudas de eucalipto com substratos para sistema de blocos. Revista Árvore, v. 34, n. 5, p. 761-770, 2010.

GOMES, J. M.; PAIVA, H. N. Viveiros florestais: propagação sexuada. Viçosa: UFV, 2006. $116 \mathrm{p}$.

INDÚSTRIA BRASILEIRA DE ÁRVORES IBA. Anuário Estatístico IBÁ 2016. Brasília: IBÁ, 2016. 96 p.

KRATZ, D.; WENDLING, I. Produção de mudas de Eucalyptus dunnii em substratos renováveis. Floresta, v. 43, n. 1, p. 125-136, 2013.

LIMA, R. L. S. et al. Substratos para produção de mudas de mamoneira compostos por misturas de cinco fontes de matéria orgânica. Ciência e Agrotecnologia, v. 30, n. 3, p. 474-479, 2006.

LÔBO, L. M. et al. Crescimento de mudas de Eucalyptus camaldulensis em resposta à fertilização NPK. Global Science Technology, v. 7, n. 2, p. 74-80, 2014.

MALAVOLTA, E.; VITTI, G. C.; OLIVEIRA, S. A. Avaliação do estado nutricional das plantas: princípios e aplicações. 2. ed. Piracicaba: POTAFOS, 1997. 319 p.

NKANA, J. C. V.; DEMEYER, A.; VERLOO, M. G. Chemical effects of wood ash on plant growth in tropical acid soils. Bioresource Technology, v. 63, n. 3, p. 251-260, 1998.

OLIVEIRA, N. G. et al. Feijão-vagem semeado sobre cobertura viva perene de gramínea e leguminosa e em solo mobilizado, com adubação orgânica. Pesquisa Agropecuária Brasileira, v. 41, n. 9, p. 1361-1367, 2006.
OSAKI, F.; DAROLTI, M. R. Estudo da qualidade de cinzas vegetais para uso como adubos na região metropolitana de Curitiba. Revista Setor Ciências Agrárias, v. 11, n. 1-2, p. 197-205, 1991.

PETTER, F. A. et al. Biochar como condicionador de substrato para a produção de mudas de eucalipto. Revista Caatinga, v. 25, n. 4, p. 44-51, 2012.

PRADO, R. M.; MEDEIROS, M. C.; NATALE, W. Efeito da cinza da indústria de cerâmica no solo e na nutrição de mudas de goiabeira. Acta Scientiarum, v. 24, n. 5, p. 1493-1500, 2002.

SEVERINO, L. S., LIMA, R. L. S., BELTRÃO, N. E. M. Composição química de onze materiais orgânicos utilizados em substratos para produção de mudas. Campina Grande: Embrapa Algodão, 2006. 5 p. (Comunicado Técnica, n. 278).

SILVA, A. R. M. et al. Efeitos de doses crescentes de calcário na produção de mudas de sumaúma (Ceiba pentandra L. Gaertn). Floresta, v. 38, n. 2, p. 295-302, 2008.

SILVA, R. B. G.; SIMÕES, D.; SILVA, M. R. Qualidade de mudas clonais de Eucalyptus urophylla x E. grandis em função do substrato. Revista Brasileira de Engenharia Agrícola e Ambiental, v. 16, n. 3, p. 297-302, 2012.

SILVA, C. J. et al. Adição de gesso agrícola e cinza de madeira ao substrato no desenvolvimento de mudas de maracujazeiro (Passiflora edulis Sims f. flavicarpa Deg.). Revista Verde, v. 8, n. 2, p. 72-76, 2013.

SILVA, R. F. et al. Produção de mudas de Eucalyptus grandis em substratos orgânicos alternativos. Ciência Florestal, v. 24, n. 3, p. 609-619, 2014. 
SOUZA, D. M. G.; LOBATO, E. Cerrado:

correção do solo e adubação. Planaltina:

Embrapa Cerrados, 2004. 416p.

XAVIER, A.; WENDLING, I.; SILVA, R. L.

Silvicultura clonal: princípios e técnicas.

Viçosa: UFV, 2009. 272 p. 